\title{
Exploring the Relationship between Dystopian Literature and the Activism of Generation Z Young Adults
}

\author{
Aysha Jerald \\ Department of English, University of Georgia, Athens, GA \\ bttps:/ / doi.org/10.33697/ ajur.2020.009 \\ Student:aij81511@uga.edu* \\ Mentor:ekraft@uga.edu
}

\begin{abstract}
Some recent research has posited that the independent and revolutionary traits of Generation Z can be traced to the circumstances of their births, specifically the $9 / 11$ attacks and the Great Recession. While there has been research examining the effect of these events on the type of behavior Generation Z exhibits towards political and societal issues, there has been little research that examines the literary culture in which they grew up. Did popular dystopian works such as Catching Fire by Suzanne Collins (2009), Divergent by Veronica Roth (2011), and The Maze Runner by James Dashner (2009) have an impact on their political identities and behaviors? This paper examines that question by using a mixed method approach: a public questionnaire, thirteen in-depth interviews with a select group of Generation Z students from the University of Georgia, and direct content analyses of the key works under consideration. This study argues that the relationship between dystopian literature and young adult activism may offer insight into the ways literature can be used as a revolutionary tool. This study also hopes to add to the literature exploring the characteristics of Generation Z and the significance dystopian literature may have not only on a young adult's thoughts but also their actions.
\end{abstract}

\section{KEYWORDS}

Dystopian Literature; Dystopian Literary Media; Generation Z; Youth Activism; Literary Influence; Activist Typology; Aspects of Literary Response: A New Questionnaire; College Students; Divergent; Catching Fire; The Maze Runner; Literary Culture, The Hunger Games

\section{INTRODUCTION}

Young adult activism is not a foreign concept to the United States. In the 1960s, the Civil Rights movement and the Vietnam War draft drew the attention of many young objectors, leading to the development of historical protests, marches, and organizations. Nearly sixty years later, with issues involving race and politics still prevalent, young adults are still actively on the move. This time, however, Generation Z stands at the forefront, armed with technological confidence and mastery.

\section{Generation Z}

Generation Z has no precise starting date. However, a rough estimate places the members to be born between 1996 and 2012. Marked with a vague concept of the American Dream, Generation Z cannot truly remember a time period before terrorism and environmental concerns existed in the world. Yet despite the dark stereotypes that surround the technologically absorbed generation, they are very interested in political and societal issues. For example, research has shown that because they do not trust elected officials, their feelings about the United States are pessimistic and dismal. However, they still believe voting is important due to strong concerns regarding inequality and the direction of the economy. ${ }^{1}$

Only recently has documentation shown Generation Z finally beginning to amplify their voices to make a difference, amidst the gun violence, gender and racial inequality, and other injustices of the current times. ${ }^{2}$ The question of where this motivation stems from has vaguely been answered, as some researchers suggest that the growing use of social media has proved itself an easier basis for activism. ${ }^{3}$ However, the literature lacks any other explanation and ignores the possibility of literature and/or literary media as a motivator as well.

As the first wave of Generation Z entered adulthood, the popularity of dystopian literature increased in parallel. A dystopia, first coined in the $1700 \mathrm{~s}$, is an imagined society depicted as undesirable, evil, or oppressive. ${ }^{4}$ The most recognizable dystopian literature within recent years has been found primarily within the young adult genre and has since been successful in the literary market. According to an article published in 2017 by The New Yorker, dystopian novels seem to be in a "Golden Age."4 Its 
attraction may be due to the reader's ability to relate to the characters, and the material being synonymous with the issues of the present.

The purpose of this study is to explore a possible connection between the activism of Generation $\mathrm{Z}$ young adults and the popularity of dystopian themes in literature and the literary media. It attempts to discover if dystopian literature has a relationship with Generation Z's mannerisms, beliefs, or values. In general, this research project re-evaluates the importance of literature and the power the Humanities may have in shaping the attitudes and behaviors of generational readers and film-goers.

\section{Readers' Dilemma}

Literature's relationship to social action may begin with examining literature's relationship to cognitive development. In 2017, a study on "readers' dilemma" examined how fictional media could shape a child's behavior. Readers' dilemma occurs when a reader must determine if a piece of information found in a fictional text or media can also apply to the real world. ${ }^{5}$ It is the process of looking past the fantastical or implausible elements of fiction to discover the realistic implications. Once the deeper theme or motif of the fiction is found, the reader may be indifferently or directly affected. If directly affected by the theme, the research suggested that the reader's real-world behavior was subject change. ${ }^{5}$ Thus, fictional media was seen not only as a means to entertain, but also a means to educate or enlighten.

\section{Literary Influence}

Psychiatrists and educated professionals have also seen and admitted to literature's influence on cognitive and social change. Based on the idea that fictional novels can provoke strong feelings of compassion and empathy within the reader, several professors have admitted to the potential use of those emotions in eliciting action. For example, results from a survey of 22,562 professors at 372 colleges found that undergraduate educators felt certain novels involving adversity could cultivate compassion, thus cultivating enlightenment and action. ${ }^{6}$ Specifically, they believed reading fictional texts combating social injustice could increase a student's likelihood to fight against a similar injustice in the real world, due to feelings the students inhabited while reading about victims of calamity. Therefore, fictional texts were seen to have the same power as factual texts, in that they both could inform the reader on previously unknown concepts and beliefs. If reading a newspaper could inspire change, then it was possible a speculative fiction novel could as well.

Dystopian Literary Influence Specifically, dystopian literature is the genre in question for this project. Can dystopian literature have a relationship with social change? While the answer has yet to be confirmed, previous research suggests a possible relationship. In an article published by Melissa Ames in 2013, it is proposed that educators should begin using dystopian literature to engage apolitical students. ${ }^{7}$ She first argues that dystopian literature may be used as a coping mechanism for modern-day students, who grew up with a more than understandable definition of terrorism, hence the $9 / 11$ attacks. ${ }^{7}$ Despite its dark content, modern dystopian literature appeals to young adults because they can relate to the metaphorical world. Themes like terrorism, dominion, isolation, and climate change found in dystopian literature can also be found in the real world. The young adult reader can connect with the characters in the novel, who suffer through the same things that they do. The novels are a type of "emotional security" blanket, which allows young adults to bear with the trauma of the real world. ${ }^{7}$

Ames also argues that reading this material may spark the revolution the authors intended to ignite within young adults. She advocates for the teaching in the classroom of social-political thematic undertones found in the novels so that students can better understand the issues portrayed. ${ }^{7}$ Then students may not only be comforted but also enlightened. In hopes that their enlightenment may lead to social action, Ames hypothesizes the positive relationship between the dystopian trend and socialpolitical engagement, especially within young adults. ${ }^{7}$

In addition to exploring the typology of Generation Z activism, this research study will also explore Melissa Ames' hypothesis. The following research questions will be addressed:

1. What is Generation Z's orientation towards literary texts?

2. Is there a relationship between the typology of Generation $Z$ young adult activists and the typology of activists seen in popular dystopian novels?

3. Is there a relationship between dystopian literature and the activism of Generation $\mathrm{Z}$ young adults? 


\section{METHODS AND PROCEDURES}

To find the answers to the research questions, a mixed method study was conducted, utilizing a Sequential Exploratory Design. The qualitative data were used to further explain the quantitative findings, which served as the forefront of the data collection. Second, a direct content analysis was conducted on three dystopian novels to discover a theoretical comparison.

\section{Quantitative Procedures}

For the quantitative portion of this mixed method study, four sections of the Aspects of Literary Response: A New Questionnaire were used. ${ }^{8}$ Prior to distribution, the proposed research and survey instrument received approval from the University of Georgia Institutional Review Board (IRB). SPSS statistical software was used to analyze the data.

The survey was administered through Qualtrics to Generation Z participants from the University of Georgia. Permission to assist with the recruitment, data collection, and to utilize data from this study was granted by the University of Georgia's Division of Academic Enhancement and Department of English. All Generation Z students were recruited through classroom presentation sampling or through email that included a hyperlink to the online questionnaire. The classrooms were provided by the University of Georgia's Department of English and Division of Academic Enhancement faculty members/professors who had agreed to participate in this study after being contacted by email. The list of student emails was provided by the university club/journal entitled The Bell and the TRIO McNair Scholars Program, as both organizations had agreed to their members' participation in this study after also being contacted by email. Before beginning the questionnaire, students were provided a consent form in which they had to agree or disagree to participating in the survey. The students' identities remained anonymous, and they were free to quit the questionnaire at any time. The questionnaire lasted approximately ten to twelve minutes. Students were offered no incentive but thanked for their willing participation.

\section{Aspects of Literary Response: A New Questionnaire}

The Aspects of Literary Response: A New Questionnaire was used to inquire about Generation Z's views, opinions, and perceptions of fictional literature/literary media. The questionnaire has seven subscales; however, only four of these subscales were used. Those scales were Insight, Empathy, Imagery Vividness, and Rejection of Literary Values. Insight contained fourteen questions, Empathy contained seven questions, Imagery Vividness contained nine questions, and Rejection of Literary Values contained nine questions. Each question was measured on a five-point Likert Scale, where 1 = "Not True At All," 2 = "Slightly True," 3 $=$ "Moderately True," 4 = "Very True," 5 = "Extremely True." The Insight section pertained to the degree to which the reader/viewer became enlightened about things they did not previously know either about themselves or the world. Statements included, "Reading literature makes me sensitive to aspects about my life that I would usually ignore" and "I often find my shortcomings explored through characters in literary texts." The Empathy section pertained to the degree to which the reader identified with the characters. Statements included, "Sometimes I feel that I've 'become' a character I've read about in fiction" and "When I read fiction, I often think of myself as one of the characters in the story." The Imagery Vividness section pertained to the degree to which the literary world became vividly present to the senses. Statements included, "I can readily visualize the persons or places described in a novel or short story." Finally, the Rejection of Literary Values section referenced the participant's rejection of literature's influence altogether. Statements included, "I think people should spend less time talking or writing about literature." All four sections were used to answer the first research question and gain an understanding of Generation Z's overall literary opinions and cognizance.

\section{Quantitative Participants}

A total of a hundred Generation Z students from the University of Georgia participated in taking the questionnaire. Of the hundred students, $70 \%$ were female and 30\% were male. The sample size consisted of $50 \%$ White students, $21 \%$ African American students, $6 \%$ Hispanic/Latina students, $16 \%$ Native American/American Indian/Asian students, and 7\% of students categorized as Other. The Generation $\mathrm{Z}$ age range consists of those twenty-three and below; however, the sample size primarily consisted of $46 \%$ eighteen-year-olds, $24 \%$ nineteen-year-olds, $17 \%$ twenty-year-olds, and 13\% twenty-one-year-olds and above.

\section{Qualitative Procedures}

Of the hundred participants who took the ALR questionnaire, thirteen students volunteered to participate in the interview portion of this study. The participants were Generation Z student volunteers who took the ALR questionnaire prior to the interview. Permission to assist with the recruitment, data collection, and to utilize data from this study was also granted by the University of Georgia's Division of Academic Enhancement and Department of English. All students were recruited via classroom presentation or email where a sign-up sheet to participate was handed out/attached. Before beginning the interviews, students were provided a consent form in which they had to agree or disagree to participating in the interview and being recorded. The interviews lasted approximately thirty to forty-five minutes. They were recorded using the Voice Memos application on an iPhone and instantly transferred to a flash drive for safe-keeping. Students were offered no incentive but thanked for their willing participation. 
Participants were asked a total of sixteen questions broken up into three different sections. The first section inquired about the student's activism and social-political opinions. Questions included, "Are you personally concerned or indifferent about socialpolitical issues" and "If you are an activist, what are your reasons for being one?" The second section inquired about the participant's literary perceptions. In hopes to understand their Aspects of Literary Response: A New Questionnaire responses in relation to dystopian literature specifically, questions included, "How do you feel when you are exposed to dystopian themes in literature or literary media?" and "Would you say you become inspired by the characters in dystopian fiction?" The interview responses from this section were used to provide justification for the quantitative findings. Finally, the third section inquired about the participants' characteristics, behaviors, and experiences that shaped who they are. Questions included, "Would you say that fear wakes you up or shuts you down?" and "Over the course of your life, do you feel as if you've become more defiant or more subservient towards society?" The third section of the interviews was a key component in discovering the participants' insurgent tendencies. It allowed for a comparison between certain Generation Z personalities and the personalities found in popular dystopian works with which they grew up with.

\section{Qualitative Participants}

Participants were thirteen undergraduates from the University of Georgia. The demographics for the interviews include seven females and six males, and seven White students, three African American students, and three Asian American students.

Direct Content Analysis

A direct content analysis was done on three popular dystopian novels of the past ten years: Divergent by Veronica Roth, Catching Fire by Suzanne Collins and The Maze Runner by James Dashner. In addition to being top selling and grossing, the novels were used because they have film adaptations, which increased the probability of their exposure to Generation $Z$ young adults. The novels were also chosen because the individuality of the protagonists, grouped with their unique dystopian environments and the rise of revolution, made for three distinct heroic archetypes. This was essential for the creation of an activist typology.

The content of the novels was coded chapter by chapter to find key elements of themes or traits relating to heroism and activism. Three different variations of activism emerged from each of the three protagonists in the novels. Using those three variations, a comparison was made between the typology of activists that exist in the novels and the typology of activists that exist within Generation $Z$ young adults, or, rather, those who were interviewed. To simplify, first, the traits, experiences, and mannerisms of each of the main protagonists in the novels were identified and listed. Then, the traits, experiences, and mannerisms of each of the interviewed participants were identified and listed. If the traits of an interviewed participant matched with the traits of a main protagonist, the interviewed participant was grouped with the fictional character and their activist type. This typology comparison was then used to examine Generation Z's activist tendencies in relation to the activist tendencies found in the characters in dystopian fiction. It also allowed and gave grounds for the third research question to be investigated in more depth. However, those theoretical comparisons will be further explored in a later part of this paper.

\section{RESULTS}

The means and standard deviations were calculated for each of the four subscales of the Aspects of Literary Response: A New Questionnaire.

\section{Quantitative Results}

The descriptive statistics for the Insight subscale showed in Figure 1 that the possible range was between 21 and 70 . The mean score was 49.78, and the standard deviation was 11.78 , suggesting that the responses were somewhere between "Moderately True" and "Very True." This meant that the students affirmed the belief that literature may guide the recognition of previously unrecognized qualities. Based on the similar responses from the interviews, this data was confirmed. The majority of the interviewed participants admitted to seeing the relationship between reality and fiction.

The descriptive statistics for the Empathy subscale showed in Figure 1 that the possible range was between 7 and 35. The mean score was 18.66, and the standard deviation was 7.45, suggesting that the mean average for the Empathy subscale, which explained the reader's ability to identify to the characters, ranged between "Slightly True" and "Moderately True."

The descriptive statistics for the Imagery Vividness subscale showed in Figure 1 that the possible range was between 11 and 45. The mean score was 29.51, and the standard deviation was 9.35. Thus, the mean average for the Imagery Vividness section, which expressed the extent to which the literary world became vividly present to the reader, ranged between "Moderately True" and "Very True."

Finally, the descriptive statistics for the Rejection of Literary Values subscale showed in Figure 1 that the possible range was between 9 and 39. The mean score was 15.00, and the standard deviation was 5.09. The mean average for Rejection of Literary 
Values ranged between "Not True At All" and "Slightly True." This meant that the majority of participants did not reject literature or its values/purpose.

\begin{tabular}{|c|c|c|c|c|c|}
\hline \multicolumn{6}{|c|}{ Statistics } \\
\hline & & Rejection & $\begin{array}{l}\text { Imagery } \\
\text { Vividness }\end{array}$ & Empathy & Insight \\
\hline \multirow[t]{2}{*}{$\mathrm{N}$} & Valid & 100 & 100 & 100 & 100 \\
\hline & Missing & 0 & 0 & 0 & 0 \\
\hline Mean & & 15.0000 & 29.5100 & 18.6600 & 49.7800 \\
\hline Median & & 14.0000 & 31.0000 & 17.0000 & 50.0000 \\
\hline Mode & & 14.00 & $32.00^{\mathrm{a}}$ & 15.00 & $52.00^{\mathrm{a}}$ \\
\hline Std. Deviatio & & 5.09307 & 9.35981 & 7.45115 & 11.78390 \\
\hline Variance & & 25.939 & 87.606 & 55.520 & 138.860 \\
\hline Range & & 30.00 & 34.00 & 28.00 & 49.00 \\
\hline Minimum & & 9.00 & 11.00 & 7.00 & 21.00 \\
\hline Maximum & & 39.00 & 45.00 & 35.00 & 70.00 \\
\hline Sum & & 1500.00 & 2951.00 & 1866.00 & 4978.00 \\
\hline \multirow[t]{3}{*}{ Percentiles } & 25 & 11.0000 & 22.2500 & 13.0000 & 42.0000 \\
\hline & 50 & 14.0000 & 31.0000 & 17.0000 & 50.0000 \\
\hline & 75 & 17.0000 & 36.0000 & 24.7500 & 57.7500 \\
\hline
\end{tabular}
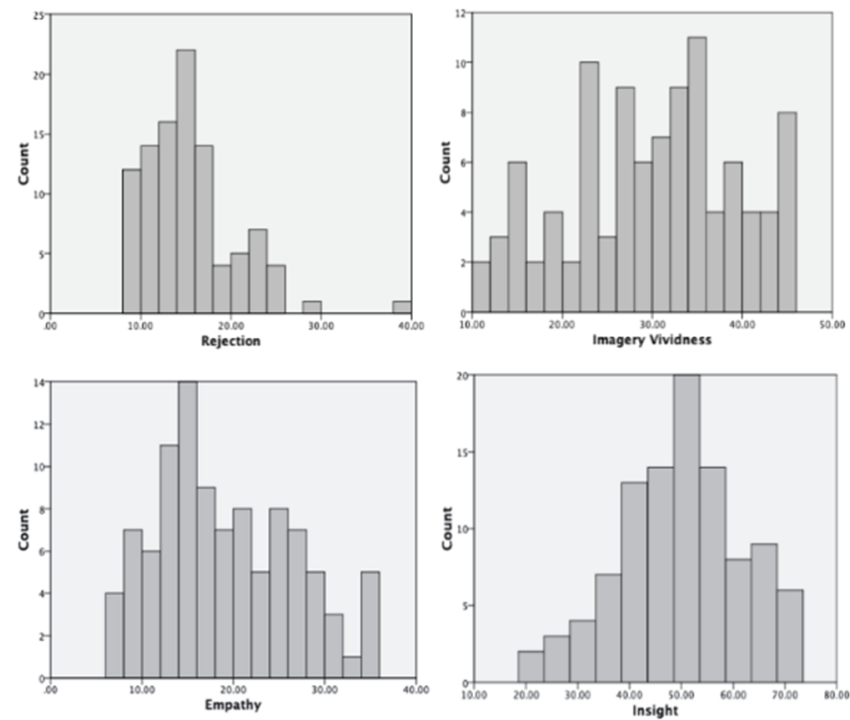

Figure 1. Reported outcomes of the subscales Insight, Empathy, Imagery Vividness, and Rejection of Literary Values with their mean averages.

A Pearson Product-Moment correlation analysis was conducted to investigate if there was any relationship between Insight and Empathy. Guided by Hopkins and Weisberg's research on cognitive development and literary influence, the suggestion was made that there was a relationship with a reader's ability to be enlightened by and/or connect with the literature..$^{5}$ As shown in Figure 1 , the Pearson coefficient was .573 and statistically significant at the .01 alpha level. This suggests a moderately strong positive relationship between Insight and Empathy. The extent to which the participant discovered things that they did not previously know about themselves had a connection to the extent to which the participant identified with the character.

Similarly, a Pearson Product-Moment correlation analysis was run to investigate if there was any relationship between Imagery Vividness and Empathy. Figure 2 shows the Pearson coefficient to be .639 and statistically significant at the .01 alpha level. The data suggests that the extent to which the literary world became vividly present to the participant had a positive correlation to the extent to which the participant identified with the character.

Correlations

\begin{tabular}{|c|c|c|c|}
\hline & & Insight & Empathy \\
\hline \multirow[t]{3}{*}{ Insight } & Pearson Correlation & 1 & $.573^{* *}$ \\
\hline & Sig. (2-tailed) & & .000 \\
\hline & $\mathrm{N}$ & 100 & 100 \\
\hline \multirow[t]{3}{*}{ Empathy } & Pearson Correlation & $.573^{* *}$ & 1 \\
\hline & Sig. (2-tailed) & .000 & \\
\hline & $\mathrm{N}$ & 100 & 100 \\
\hline
\end{tabular}

Correlations

\begin{tabular}{llrr} 
& & & \multicolumn{1}{c}{$\begin{array}{c}\text { Imagery } \\
\text { Vividness }\end{array}$} \\
\hline Empathy & Pearson Correlation & 1 & $.639^{* *}$ \\
\cline { 2 - 4 } & Sig. (2-tailed) & & .000 \\
\cline { 2 - 4 } & $\mathrm{N}$ & 100 & 100 \\
\hline Imagery Vividness & Pearson Correlation & $.639^{* *}$ & 1 \\
\cline { 2 - 4 } & Sig. (2-tailed) & .000 & \\
\cline { 2 - 4 } & $\mathrm{N}$ & 100 & 100 \\
\hline
\end{tabular}

$*$. Correlation is significant at the 0.01 level (2-tailed).

Figure 2. Reported outcomes of the Pearson Product-Moment correlation analysis for the subscales Insight and Empathy and Imagery Vividness and Empathy.

The Pearson Product-Moment correlation found weak correlations as well. In regards to the relationship between Rejection of Literary Values and Imagery Vividness, Figure 3 shows the Pearson coefficient to be .056 and without significance. This implied that the participants who rejected the values found in literature were not shown to have feelings of enlightenment or a sensory connection towards the text. Similarly, the Pearson Product-Moment correlation ran to also expose the relationship between Rejection of Literary Values and Insight had a coefficient of -.142 as displayed in Figure 3. This showed that the participants who rejected the values found in literature did not necessarily have a connection to the characters found in fiction. 


\section{Correlations}

\begin{tabular}{llr|r} 
& & \multicolumn{1}{c}{$\begin{array}{c}\text { Imagery } \\
\text { Vividness }\end{array}$} & Rejection \\
\hline Imagery Vividness & Pearson Correlation & 1 & .056 \\
\cline { 2 - 4 } & Sig. (2-tailed) & & .579 \\
\cline { 2 - 4 } & $\mathrm{N}$ & 100 & 100 \\
\hline \multirow{3}{*}{ Rejection } & Pearson Correlation & .056 & 1 \\
\cline { 2 - 4 } & Sig. (2-tailed) & .579 & \\
\cline { 2 - 4 } & $\mathrm{N}$ & 100 & 100 \\
\hline
\end{tabular}

\section{Correlations}

\begin{tabular}{ll|r|r} 
& & Rejection & \multicolumn{1}{c}{ Insight } \\
\hline Rejection & Pearson Correlation & 1 & -.142 \\
\cline { 2 - 4 } & Sig. (2-tailed) & & .158 \\
\cline { 2 - 4 } & $\mathrm{N}$ & 100 & 100 \\
\hline \multirow{3}{*}{ Insight } & Pearson Correlation & -.142 & 1 \\
\cline { 2 - 4 } & Sig. (2-tailed) & .158 & \\
\cline { 2 - 4 } & $\mathrm{N}$ & 100 & 100 \\
\hline
\end{tabular}

Figure 3. Reported outcomes of the Pearson Product-Moment correlation analysis for the subscales Rejection of Literary Values and Imagery Vividness and Rejection of Literary Values and Insight.

In summary, the quantitative data provided a small view of Generation Z's literary values. Through the descriptives shown in the Insight, Empathy, and Imagery Vividness sections, it is inferred that they have a "Moderately True" opinion towards literature's influential and relational capabilities. Additionally, they do not generally reject literature's purpose or values, and the interview responses provided a more in-depth explanation as to why, with dystopian fiction in mind specifically. Eleven out of the thirteen participants agreed that dystopian literature had significance. Yet the question of personal significance was not specifically answered. It was not until a direct content analysis on three popular dystopian novels was conducted that the qualitative data began to suggest an influential relationship. It also began to suggest a typology.

\section{Qualitative Results: An Activist Typology}

Three categories of Generation $\mathrm{Z}$ activism arose from this study, all of which can be compared to the typology of activism seen in recent dystopian literature and literary media. The three categories are as follows: the Selfless Activist, the Reluctant Activist, and the Instinctual Activist. Thirteen Generation Z students were interviewed, yet only twelve fit into a category that provided an explanation for their drive and provocations. The outlier participant of this study will be further investigated and explained in the discussion section of this paper.

\section{The Selfless Activist}

Three out of the thirteen participants of this study were categorized as selfless activists. Lawrence A. Lengbeyer describes selflessness as "setting aside concerns for oneself, out of concern for others." It is the notion that encompasses self-sacrifice, whether mentally or physically, so that another can be comforted or provided for. Selflessness is more or less an aspect of heroism, as it consists of bravery that results from a lack of self-regard. As opposed to the champion-like doctrine that typically defines heroism, the characteristics of the selfless activist refer to mediocre acts like standing up for someone in a distressed situation or speaking for a cause that does not personally affect them..$^{10}$ It gives a platform for the "realistic hero," or someone who does the right thing without possessing outstanding traits and abilities. ${ }^{10}$ Instead, they use personal and moral values, but they allow their selflessness to dictate their actions.

Selflessness is also an emphasized theme in Veronica Roth's Divergent series. Throughout the first novel, the protagonist Tris Prior undergoes a variety of tests to analyze her mental and physical abilities. In all of the cognitive and physical assessments, Tris acts without regard for herself, essentially ignoring her fear to protect and/or save another. ${ }^{11}$ The author means to imply that selflessness often leads to bravery, or that the two terms are synonymous. ${ }^{11}$

The first novel was published in 2011 and the first film was produced in 2014. Nine out of the thirteen participants said they have seen the film and/or read the novel in their youth, including the three mentioned below. Overall, the participants' perceptions of the novel ranged from indifference to reflective. For example, Participant 4 gave her thoughts on what she gathered from the story:

I felt the idea of Factions was pretty reflective of our society ... I feel like how they divided themselves so strictly and kept themselves in boxes and the fight for leadership was kind of reflective of what I've seen today ... What's legal may not always be right; the laws may not be fair.

When asked about their reason for being involved in protesting or advocating against certain social-political issues, the three participants talked about various causes. Participant 2 spoke on her White Privilege and how it should be handled. Aware of the social advantages, she explained that those with privilege need to use their benefits to help others. They should not be selfish with their privilege and instead use their special right to help those without. Similar to Tris from Divergent, who sees "guilt as a tool, 
rather than a weapon against the self," Participant 2 recognized the use and value of guilt by association. ${ }^{11(p 315)}$ For example, she states,

I know that I have privilege and that's not something I can personally help, but it's something I can use to other people's advantage. I think it's important that when we do have some sort of privilege to use it to help those who are disadvantaged by the same system that we're advantaged by. And I think that being politically active is part of that and without people voting and [working] to change legislature and politicians then ... the privilege will never go away and people won't have the same privilege that [1] do ... It's my civic duty to help those whose voices aren't heard as loud as mine.

The progressive attitudes of these Generation Z participants were reflected in their responses, as concepts like "White Privilege" and oppression became less of a quickly-avoided topic of discussion. Additionally, the participants openly acknowledged the necessity of change as a means to fix the indifference and mistakes of the generations that came before them. In Roth's Divergent, an older character recollects, "Decades ago our ancestors ... divided into factions that sought to eradicate those qualities they believed responsible for the world's disarray."'11(p42) In Tris's world, the older generation believed that conforming one's personality was the best way to establish peace. However, Tris later discovers that her ancestors were wrong, and she intends to fix her outlook on separated personalities. She says, "I feel like someone breathed new air into my lungs. I am not Abnegation. I am not Dauntless. I am Divergent." "11(p442) Tris considers herself renewed and finds a sense of self-agency. She intends to go her own way instead of the way others have paved for her. This independence in thought, brought on by defiance, was also found within the participants of this study who were categorized as selfless activists:

I feel like it's my responsibility to try and fight for better circumstances for other people. And I feel like, as a younger generation, we can't just accept that the older generation knows everything, or that they know what's best. We have to accept that they've made mistakes, and we might have to fix them. (Participant 4)

The selflessness that exists in these participants is often a product of their relationships. As the world gradually grows more and more diverse, diverse relationships are likely to occur. Through those relationships, perceptions are broadened and viewpoints are subject to change. As one begins to sympathize with the difficult experiences of their peers, they may also begin to advocate for change along with them. Thus, the selfless activists are those who are willing to put themselves in uncomfortable positions for the betterment of others despite having no direct connection to the issue. An advocate for taking action, Roth's protagonist comes to believe "in the ordinary acts of bravery; in the courage that drives one person to stand up for another." 11(p207) Gathered from the data, it was found that the selfless activists of this study believed that same notion:

One of my teachers, she gave a quote the other day in class, or maybe a couple of weeks ago, where she said, "I think your generation ... is the first the first in a while to care about something other than themselves." And, I would agree with that, very strongly. I think we do care about stuff other than ourselves ... For example, if I had a teammate who felt called to kneel for the national anthem at a game and was under some type of ridicule, I would stand by them, especially if I thought their cause was noble. (Participant 13)

These participants are examples of the "realistic heroes" that exist in the world. They are the citizens who make a difference every day by standing up for their peers and openly speaking out against the things they disagree with. As Lawrence A. Lengbeyer explains, their selflessness is "uncalculated," and they behave courageously by shutting "out of one's cognizing certain considerations that, if taken fully seriously, would arouse fear." Having grown up in a world of terrorism, war, and political unrest, Generation $\mathrm{Z}$ is familiar with fear. However, they are also familiar with change -for themselves and others. ${ }^{1}$

\section{The Reluctant Activist}

Five out of the thirteen participants of this study were categorized as reluctant activists. The reluctant activist describes the participants who were first hesitant towards advocating for social-political issues. Later, their feelings of indifference or disinclination were overshadowed by their insurgency and realization for the need for social change. Typically, when a person's attitude changes from that of indifference to that of concern, it is due to a shift in "self" or an overwhelming surge of emotion that then drives their activism. ${ }^{12}$ As opposed to the confident, "born" activist, the reluctant activist is circumstantial or accidental. A series of unfortunate events would have drawn them to different perspectives, specifically those events that were deemed climactic for the individual. In a study done by Tracey Ollis entitled The Accidental Activist: Learning, Embodiment and Action, it was found that emotions like anger and frustration account for the change in purpose and desire for better circumstances, as did collectivity. ${ }^{12}$ Essentially, the activists become subject to a "turning point" and then are drawn to revolutionary movements. 
This type of activism is also found in Suzanne Collins' The Hunger Games trilogy, specifically in the second novel of the trilogy, Catching Fire. As opposed to the first novel, the prospect of revolution and societal disobedience becomes more prevalent in Catching Fire. While in The Hunger Games the rebellious attitude and insurgence of the protagonist Katniss Everdeen is shown, it is not until the second novel when the rebellious attitude and insurgence of the dystopian society is shown. Catching Fire was analyzed instead of The Hunger Games because the novel demonstrates the formation and progression of an uprising, and a young activist's response to a quickly changing world. ${ }^{13}$ In a way, the demonstrations, protests, and revolts that transpire in Catching Fire mirror the demonstrations, protests, and revolts that have transpired in the real world. Thus, the Katniss that exists in Catching Fire can then be compared the Generation $\mathrm{Z}$ young adults that exist in the real world.

A common theme found in the novel is the struggle between reluctance and willingness. Due to having already been awakened to the true horror of the world, Katniss longs for normalcy and wants no part in a rebellion. ${ }^{13}$ However, the possibility of a social change being brought forth secretly excites her. In the beginning of the novel, during a conversation with the antagonist President Snow, Katniss is "chilled and somewhat elated by the possibility" of an uprising. ${ }^{13(p 21)}$ Yet, Katniss is still hesitant to take action, and she does not speak out against injustices of her world, although she knows they exist. It is until she witnesses the government's unfair and brutal treatment of a friend when the heroine's rage gives her the strength to defy. ${ }^{13}$ Her friend's sufferings, as well as the sufferings of those around her, lead her to accept and take part in the rebellion. ${ }^{13}$ She decides to stop running away from the issues of the world and to confront them. For instance, Katniss says, "At some point you have to stop running and turn around and face whoever wants you dead." 13(p118) She then decidedly tells her friend Gale, "I'm not going anywhere. I'm going to stay right here and cause all kinds of trouble." 13(p119)

Catching Fire was published in 2009 and the first film was produced in 2013. Ten out of the thirteen participants said they have seen the film and/or read the novel in their youth, including the four mentioned below. Overall, the participants' perceptions of the novel can be summarized as inspirational. For example, Participant 6 gave her thoughts on how she felt about the story:

I think that I was able to place myself in [Katniss'] shoes, and I kind of saw why she acted the way she did ... [I'm] encouraged. Because I feel the same anger that [the characters] feel when things happen to them.

The case of the reluctant activist is complex, as it may take a while for the activist to reach that emotionally-charged transitioning point. Often, they start reluctant for fear of the movement. This fear is often due to belief in the government's indifference or intervention. Also, the fear may be due to the intimidating and aggressive mood which often characterizes some demonstrations. In Suzanne Collin's Catching Fire, Katniss describes a horrendous scene following a speech she gives to a crowd of people. ${ }^{13}$ While she does not intend to encourage an act of civil disobedience, her audience "presses the three middle fingers of their left hand against their lips and extend them" in a public salute to Katniss, the "girl who defied the Capitol." 13(p61) The gesture, though simple, fills Katniss with fear, because she knows she has "elicited something dangerous." 13(p62) In the scene, turmoil and violence breaks out between the people and the Capitol's police officers, and the idea of an uprising appears more detrimental to Katniss, who at first feels "acts of dissent" should be defused instead of supported. ${ }^{13\left(\mathrm{p}^{62}\right)}$ Participant 1 of this study, who later found his mode of activism to be more small-scale than large-scale, describes a similar event and feeling. While observing an anti-Trump protest on campus, the participant talks about an incident that made him reluctant to join the movement:

On the rally [when] one of the Trumps was coming in ... my friend and I were walking past that event and he was wondering whether or not he wanted to go protest. But as we walked by, the [protesters] that were there were being very hateful and spiteful and calling us out for not immediately jumping in ... So, that's why I wouldn't want to get involved with any of that. A good cause could turn into a reason to be rowdy.

Other participants spoke on their dissatisfaction of the world as a reason for their resistance. However, their dissatisfaction also served as a catalyst. The "turning point" for more than half of the participants was the 2016 election of Donald Trump as the forty-fifth president of the United States. Specifically, the reluctant activists of this study spoke about their immense frustration with the event, and how they began to rethink their personal values in the years that followed. Like Katniss Everdeen, the participants believed their leader unfit, for his speech also gave the impression that "his primary concern is the welfare of the citizens ... when nothing could be further from the truth." ${ }^{13\left(\mathbf{p}^{22}\right)}$ For example, Participant 5 spoke on how his political platform changed in response to the election:

I grew up in a conservative, Christian household ... [After the election] I began to look at how society and the government kind of meshed in a more broad view and kind of understand how history led to some of the problems that we currently face today, as well as how our society has molded. That's when I became a bit more libertarian. 
While government changes served as one type of catalyst for most participants, society and interpersonal relationships are contributing factors as well. When the "I" mentality turns into a "We" mentality, it is often due to the influence of peers. The emotions or enlightening that comes about towards social-political issues typically follows a conversation and/or an interaction with others who have more insurgent personalities, thus the individual is forced to contemplate differing viewpoints. ${ }^{14}$ Collective action is an absorbing force, and it succeeds in channeling and redirecting emotions of frustration to collectivity. ${ }^{14}$ This kind of redirection is also seen in Catching Fire. Influenced by the insurgent actions of her friend Gale, Katniss says, "Gale is right. If people have the courage, [a rebellion] could be an opportunity. He's also right that, since I have set it in motion, I could do so much." 13(p123) While explaining his rise to activism, Participant 10 talked about how he was drawn to collective action by his environment and society:

Before the semester, I wouldn't have considered myself politically involved, [then] I was influenced by society ... [Now], I'm a part of YDSA, Young Democratic Socialists of America. I've [even] been a part of a committee that designed a survey to hand out to the community members gauging their well-being in the community and what policies they think will increase their well-being.

The emotions and testimonies of reluctant activists can be described as progressive and transformational. Similar to the fictitious character Katniss Everdeen from The Hunger Games trilogy, their insurgency "caught fire," having been triggered by an eyeopening event and/or the influence of peers. While their turn towards the movement was gradual, it was a defining moment for each, summarized as an "awakening" for many. However, this process is not abnormal for Generation Z, who's once disengaged and "lackluster" view of the country is now beginning to turn into something different. ${ }^{1}$

\section{The Instinctual Activist}

The final type of activist that arose from this study was the instinctual activist. Unlike the previous types, instinctual activists are not activists due to personal "turning points" or selflessness towards a minoritized group. Instead, their insurgency is a trait that they are "born" with. The term defines a person whose acts of defiance are instinctual and impulsive, usually without reason or contemplation, and a result of curiosity and oppression. Four out of the thirteen participants in this study were categorized as instinctual activists because they moved recklessly, yet passionately, driven by motivation and a desire for something more.

An instinctual activist is also a term one could use to describe Thomas, the protagonist in James Dashner's The Maze Runner. A common theme found in the novel is the redefining of identity and the transformation of fear into something useful. From the first chapter and onward, Thomas's impulsive insurgence is a hybrid combination of fear and curiosity. He refuses to accept the normalcy of the boxed, maze-like world and seeks liberation immediately. His actions are reckless, yet instinctive, as an urge to take some sort of action overwhelms him. For example, after becoming enlightened by the horrid state of the world, Thomas immediately seeks liberation and change. When he learns about the tasks of the "Runners," or people who run through the maze each day to find a way out, Thomas instantly feels like the job was made for him. ${ }^{15}$ Despite others' warnings that the task is dangerous and unattractive, Thomas is drawn to it. Even when he sees the danger of the job himself, he remains rooted in his conviction, for it "called to him as much as hunger and thirst." ${ }^{15(\mathrm{p} 46)}$ In a sense, he is driven by a motivational desire for freedom.

The Maze Runner was published in 2009, and the first film was produced in 2014. More than half of all participants said they have seen the film and/or read the novel in their youth, including two out of the four mentioned below. Overall, the participants' perceptions of the novel can be summarized as positive and reflective. For example, Participant 12 gave his thoughts on how he felt about the story:

Sometimes you don't catch it at first. As you engage in the story, you start to understand this is what they really mean. In the first movie, your viewpoint on their lives was one way, and as the story kept building on, you started to change your viewpoint. I feel like that same thing would be true if you brought that out to the real world because most people are ignorant to the things they just haven't experienced themselves ... I really love [The] Maze Runner. That's my favorite.

The traits of an instinctual activist can often be spotted at a young age. As explained by Darwin, instinct and impulse usually encompass the young, and the justifications for their actions may not even be known. ${ }^{16}$ However, that instinctual spirit may not fade away with time. Since instinct is often correlated with curiosity, those who remain curious later in their lives may also remain instinctive. ${ }^{15}$ Curiosity allows one to question the unknown. It was found in this study that curiosity also allows one to question societal norms and customs that may be opposed to a common, social belief. In The Maze Runner, Thomas was labeled a "rule breaker" because his curiosity caused heroic, yet rebellious tendencies. ${ }^{15(\mathrm{p} 152)}$ Similar to the instinctive activists of this study, Thomas "felt his fear whisked away like a swarm of gnats caught in the wind, replaced by an intense curiosity" for his world and 
its subjective formalities. ${ }^{15(\mathrm{p} 2)}$ For example, Participant 11 spoke of her opinion on the controversy surrounding the pledge of allegiance:

People are finally realizing that the pledge of allegiance is foolish. When I was younger, I was like, why do we have to stand up and do this? I don't actually care about anything they're saying. They don't care about me [as an African American]. I stopped standing after a while. I used to get in trouble for not standing, but eventually they stopped requiring me ... I've always been defiant. I can't even explain it. It's just my natural tendency.

An instinctual activist may impulsively or instinctively advocate for a social-political movement that pertains specifically to their experiences. For example, while participants of this study pronounced that they cared about a wide range of issues, they advocated more so for personal offenses, like race, gender, and/or LGBTQ issues. They were quick to comment on their personal state of affairs, and they explained how their environments shape their personality. For instance, Participant 3 stated her opinion:

I've always been very defiant towards men wanting me to be subservient to them. That relates as a whole to me being defiant towards society, because society is the patriarchy ... [My response] is always to keep fighting. I don't want to be subservient in any part of my life.

The theme of "fighting" was a constant theme among the instinctual activists of this study, whose instinct to take action was almost as defined as their determination to create change in the world. In an article written by Caroline Myss, she explains the hidden truths of heroism. In its modern form, a hero is a person "who knows how to count on his own inner resources, his own instincts, his own fight-or-flight mechanism."17 Because they rely on the voice in their head, they are survivors, for they know their truth and act accordingly by using their instincts. ${ }^{17}$ In Dashner's The Maze Runner, Thomas exemplifies this type of heroism on several occasions. ${ }^{15}$ In justification for his and his friends' heroic acts, Thomas says, "Most people would've given up by now. But I think we're different. We couldn't accept that a problem can't be solved ... And we've kept fighting no matter how hopeless it's gotten." $15(\mathrm{p} 305)$ Likewise, Participant 12 of this study connects his instinctive behavior to activist/heroic behavior in the following statement:

I guess I have a fight response more than a flight response. Even if you run away, nothing changes. Ignoring your problems doesn't make the problem go away ... [For example], when I see wrongs being done in my view or hear about them I try to actively make a change. Whether it's small or a big change ... I don't think as a whole that [my generation just has] no power. I feel like we do. It's kind of like we're all superheroes, but we just haven't realized it yet.

The testimonies and statements of the instinctual activists can be deemed just as insurgent as their personalities and experiences. Coincidently, all participants who were categorized as this type were of a minority group, causing their statements to be more radical than the rest. However, similar to the character from James Dashner's The Maze Runner, they entered into this world feet first, running towards liberation in an otherwise confusing and disgruntled world. Unlike the former types, the instinctual activist has a more personal motive. They are neither fighting for the sake of others nor undergoing a transformative process. Instead, equipped with curiosity and motivational desire, they fight for themselves, as it is their instinct to do so.

\section{DISCUSSION}

As there has been relatively little research pertaining to dystopian literature's relationship with activism, specifically in regards to Generation Z, this research aimed to shed light on the genre's implications. In accordance with the rise of dystopian literature within the last decade, the results of this study were to be expected. Since the hundred Generation $Z$ participants who took the questionnaire were of those who grew up during a time of terrorism, financial crisis, media manipulation, and social-political unrest, ${ }^{1,7}$ the findings from this study suggest an interesting relationship between Generation Z members and the dystopian worlds and characters.

The interviewed participants described dystopian literature/literary media as synonymous to the real world. In regards to the Insight and Imagery Vividness subscales, the realization that the dark themes addressed in the fiction paralleled those in the real world dawned on the participants the more they engaged with the storyline. They began to visualize the world and its symbolism and described it as "too real" or a "reflection" of society. Participants also noted how the exposure to dystopian narratives lead to the discovery of previously unrecognized qualities within themselves. For example, Participant 12 expressed how Thomas in The Maze Runner made him realize that if he had a stance for something, then he had the ability to overcome any adversity that came in his way. Similarly, Participant 4 expressed how Katniss in The Hunger Games trilogy inspired her to speak out even if her life or 
reputation were in danger. Thus, reflecting on the life of a fictional character allowed participants to reflect on their own lives. They recognized that insurgence was not a fictional trait but a real one.

The Empathy subscale was also justified by the responses found in the interviews. Participants were not only discovering qualities about themselves and their world that were previously unknown. They were also discovering a new identity, guided by the identities of the fictional characters in dystopian literature/literary media. The research by Justin Scholes and Jon Ostenson (2013) found that dystopian fiction's appeal to Generation Z young adults was due to the content's familiarity. ${ }^{18}$ The fictional characters who lived in a type of backward situation, environment, and/or world mirrored that of young Generation $Z$ members, who were also in the stages of questioning both themselves and "the underlying values of a flawed society." 18 Therefore, Generation $Z$ members did not only understand the characters, but they identified with them. For example, Participant 6 addressed her relation to Katniss in The Hunger Games trilogy in that she also felt the same anger and frustration towards the government as the character did towards hers. Another participant, Participant 11, also expressed her relation to and admiration for Katniss, since the character rose from poverty to wealth in an inspirational way.

The Rejection of Literary values subscale scored a low mean average, with the responses ranging between "Not True At All" and "Slightly True." According to the questionnaire participants, the themes and storylines that exist in literature and the literary media are not generally ignored or deemed irrelevant, and twelve out of the thirteen interviewed participants expressed their reasoning as to why. The majority of the participants felt that it was important to see the themes in dystopian literature since they are so reminiscent of society. Since dystopian literature typically portrays what the future could be, the participants perceived the fiction as a warning. For example, Participant 4 stated that dystopian literature showed her how to be mindful of corrupt leaders, as the wrong leader could make a decision that negatively affects the world. Yet, interviewed participants also noted how dystopian literature is important in that it both projects and eases their fears for the world. Although the world may become dark and oppressive, it can also always be saved and revolutionized.

\section{A Typology Theory}

The findings from this study also suggest that the activism of Generation Z young adults relates to the activism found in the dystopian literature/literary media with which they grew up with. The theme of revolution is prevalent and popular in several YA dystopian novels and films, including in Divergent, Catching Fire, and The Maze Runner. Despite the harsh, oppressive world, the protagonist almost always prevails against the corrupt government, society, science, or technology that once abused them. Based on the direct content analysis of this study, the dystopian literature's protagonists' activism or insurgency was generally described as one of three: selfless, reluctant, or instinctive. Coincidentally, the activism of some Generation Z members may be described as the same. The interviews from the qualitative portion allowed a relationship to exist between the typology of activism found in dystopian literature/literary media and the typology of activism found in Generation Z young adults.

An outlier from the qualitative portion of this study allowed for another relationship to exist. While the majority of the thirteen interviewed participants of this study were able to be categorized in their activist type, one participant was not categorized at all. The specific participant, Participant 8, did not exhibit activist traits and did not hold any specific progressive or activist beliefs. Also, Participant 8 showed neither interest in nor previous exposure to dystopian literature/literary media. Based on what was discovered in the quantitative portion of this study, in regards to the Rejection of Literary Values subscale from the questionnaire, those who rejected literature or its importance were also shown to reject a connection with the characters or literary world. Therefore, since a connection did not exist between Participant 8 and dystopian literature/literary media, Participant 8 lacked the ability to become inspired by revolutionary-themed fiction. While it cannot be confirmed that Participant 8's lack of socialpolitical justice was due to a disinterest in literature, a pattern was formed from the data. Whereas the interviewed participants who expressed an appreciation for dystopian literature/literary media represented an activist type, the interviewed participant who did not express an appreciation for dystopian literature/literary media did not contain an activist type.

\section{CONCLUSIONS}

Although this research puts forth an idea that ought not to be ignored, it is not definite that this research proves that Generation Z's activism has an influential relationship with dystopian literature and/or literary media. However, there is a kind of relationship that does exist, if not influential. The qualitative data attested that the activist traits of Generation $Z$ young adults are similar to the activist traits of literary characters in the dystopian fictions Divergent, Catching Fire, and The Maze Runner. Also, the qualitative data, paired with the quantitative data, attested that dystopian literature is not a neglected source of inspiration. While there are many factors that could lead a Generation Z member to activism, like cultural experiences and personal phenomenon, this study means to insert the possibility of another factor. Still, there are several important limitations of this study to consider before such an insertion receives validation. 


\section{Limitations and Implications}

One limitation of this study was the lack of literature around speculative fiction's influence on activism. While it is known that personal experiences can impact one's level of insurgence towards social-political issues, it is less known that literature/literary media can have an impact as well, especially in regards to a generation of people. Also, it is not likely that literature alone, regardless of the genre, can influence one's activism. It is more likely that one's background, culture, and environment would trigger or be the reasoning behind activism. For example, the minorities in this study were more likely to be influenced by their marginalization rather than their interest in insurgent-type literature. The racism, discrimination, and oppression experienced by those participants, as well as towards their people, would have motivated them to adopt an activist or insurgent behavior. Similarly, the revolutionary culture of the world, characterized by demonstrations, marches, and speeches made in advocating for civil rights, would have also influenced those participants to become activists, as they would have seen how change should be advocated. ${ }^{2}$ Frankly, the revolutionary culture of the world would have also influenced non-marginalized groups of people, including some of the participants in this study, who attributed their insurgence to their desire to see change occur for the betterment of their oppressed peers. In this regard, speculative fiction or dystopian fiction may neither be one of the reasons nor the sole reason for influencing one's activism.

In addition, another limitation of this study is its dependence on self-reported data. The qualitative portion of this study leaned heavily on the responses from the interviewed participants, who may or may not have truthfully reported their activist experiences and literary beliefs. Similarly, the majority of the interviewed participants openly identified as either Democrat, Liberal, and/or Libertarian. Due to their political identities, it is likely that the participants self-selected themselves to be interviewed because they distinguished themselves as an activist. It is also likely that the participants agreed to take part in the study because they had an interest and/or were a fan of the dystopian genre in literature and literary media. Thus, their willingness to participate in the qualitative portion of this study may have contributed to their anti-conservative, progressive mindsets as well as their inclination towards speculative fiction. The limitation creates a bias in data collection from the interviews and doubts any claims of causality between reading about dystopian fiction and activism since not all Generation Z young adults consider themselves activists and/or attracted to the literary genre.

In regards to the quantitative portion of this study, the limitations existed in the sample size and questionnaire content. The sample size for this study was only a hundred participants. A larger sample size would give more accurate mean values, identify more outliers, and overall contribute to a higher confidence level. A larger sample size would also give a more general synopsis of Generation Z's literary perceptions as a whole generation, including those not categorized as young adults. It is an important limitation to note that the quantitative data, as well as the qualitative data, in this study was collected by young adults and college students, which is a mere subset of the Generation Z population. This subset of Generation Z does not in any way reflect Generation $Z$ as a whole or the interests/activist traits of Generation Z as a whole.

The questionnaire content of this study served as a limitation in that it focused on Generation Z's perceptions of literature instead of primarily the dystopian genre. Additionally, the content could have done more to comply with the qualitative portion of this study, which inquired more so on the activism of Generation Z members. Perhaps, as a suggestion for future research, the survey instrument could include questions about Generation Z's dystopian literary perceptions in relation to their activist characteristics. Then, the research would be given a more direct answer in regards to literature's influential relationship with activism. The typology of activists found in the qualitative portion of this study would also benefit from that addition, as the questions relating to their activist characteristics would confirm the extent to which it was selfless, reluctant, or instinctive.

\section{Final Notes}

The main conclusion to be drawn from this research is dystopian literature's potential significance in encouraging/shaping the progressive mindsets of its audience. It is certain that Generation Z young adults and children have been surrounded by fictional dystopian storylines in literature and in the literary media for the past decade. Along with the contemporary favorites, classical narratives like The Giver and The Handmaid's Tale have been revived and publicized for their viewing, and the surge of others has not gone unnoticed. Although the dark themes tell stories of oppression, they also tell stories of revolution. They define resilience as the idea that change can be facilitated by anyone as long as there is a passion to drive it.

Consequently, instead of dismissing dystopian literature as an attractive entertainment medium, the public should consider the fiction as an inspirational tool. For whatever enlightens and influences Generation Z also enlightens and influences the future. Therefore, if dystopian novels full of revolutionary promise and change have truly captivated Generation $\mathrm{Z}$ young adults, then the world is already in better hands than imagined. 


\section{ACKNOWLEDGEMENTS}

This project was supported by the TRIO McNair Scholars Program at the University of Georgia. The author thanks Dr. Elizabeth Kraft, Dr. Chris Pisarik, Dr. Mylene Culbreath, and all the participants of this study.

\section{REFERENCES}

1. Dorsey, J. (2016). iGen's Political \& Civic Outlook. Retrieved from bttp://genhq.com/mp-content/uploads/2016/02/iGen-Gen-ZPolitical-Civic-Outlook-Research-White-Paper-c-2016-The-Center-for-Generational-Kinetics.pdf

2. Pimentel, J. (2018, June 1). 15 young activists who are changing the world. Complex. Retrieved from https:// wnw complex.com/ life/young-activists-who-are-changing-the-world/ jack-andraka

3. Elliott, T., and Earl, J. (2018). Organizing the next generation: Youth engagement with activism inside and outside of organizations. Social Media + Society. https:// doi.org/10.1177/2056305117750722

4. Lepore, J. (2017, May 29). A golden age for dystopian literature. The New Yorker. Retrieved from bttps: / / wnw.newyorker.com/ magazine/2017/06/05/a-golden-age-for-dystopian-fiction

5. Hopkins, E. J., and Weisberg, D. S. (2017). The youngest readers' dilemma: A review of children's learning from fictional sources. Developmental Review, 43, 48-70. https:// doi.org/10.1016/j.dr.2016.11.001

6. Nance, K. A. (2010). Reading human rights literature in undergraduate literature classes: Professorial desire, disciplinary culture, and the chances of cultivating compassion. Journal of Human Rights, 9(2), 161-174. bttps:// doi.org/10.1080/14754831003761670

7. Ames, M. A. (2013). Engaging "apolitical" adolescents: Analyzing the popularity and educational potential of dystopian literature post-9/11. Faculty Research \& Creative Activity, 11. http:/ thekeep.eiu.edu/ eng fac/11

8. Miall, D. S., and Kuiken, D. (1995). Aspects of literary response: a new questionnaire. National Council of Teachers of English, 29. Retrieved from https:// monw.jstor.org/stable/40171422

9. Lengbeyer, L. A. (2005). Selflessness \& cognition. Ethical Theory and Moral Practice, 8(4), 411-435. https:/ / doi.org/10.1007/s10677-005-8838-0

10. Keczer, Z., File, B., Orosz, G., \& Zimbardo, P. G. (2016). Social representations of hero and everyday hero: a network study from representative samples. PLoS ONE, 11(8), 1-17. https:// doi.org/10.1371/journal.pone.0159354

11. Roth, V. (2011). Divergent. Katherine Tegen Books.

12. Ollis, T. (2008). The accidental activist: Learning, embodiment and action. Australian Journal of Adult Learning, 48(2), 316-335.

13. Collins, S. (2009). Catching Fire. Scholastic Press.

14. Eyerman, R. (2005). How social movements move, in Emotions and Social Movements (Flam, H., and King, D., Eds.) 1st ed., 4156 , Routledge.

15. Dashner, J. (2008). The Maze Runner. Delacorte Press.

16. Burghardt, G. M., and Jr, R. W. B. (2018). Wallace Craig's appetites and aversions as constituents of instincts: A centennial appreciation. Journal of Comparative Psychology, 132(4), 361-372. http:// dx.doi.org/10.1037/com0000155

17. Myss, C. (2014). What is a hero? KidSpirit Magazine, 80-82.

18. Scholes, J., and Ostenson, J. (2013). Understanding the appeal of dystopian young adult fiction. The ALAN Review, 40(2). bttps:// doi.org/10.21061/alan.v40i2.a.2

\section{ABOUT STUDENT AUTHOR}

Aysha Jerald is currently an undergraduate junior pursing an A.B. in English, a B.S.Ed. in English Education, and a certificate in New Media Studies at the University of Georgia. She plans on attending graduate school to obtain a Ph.D. in Comparative Literature, and she intends to pursue a research career in digital media and literary influence.

\section{PRESS SUMMARY}

Although primarily an entertainment media, dystopian literature and film have drawn the attention of many readers and filmgoers, especially those within Generation Z. In fact, recent studies have shown that Generation Z is particularly interested in the dark, fictitious genre, as the themes that exist in the literary world also exist in the real world. This research studies that connection and its implications, specifically in regards to Generation Z's activism and activist characteristics. It is posited, from this study, that the insurgent and revolutionary traits of the youngest generation could be linked to dystopian literary impact and exposure. Since radical and progressive book series and movies like Divergent, The Hunger Games, The Maze Runner, and others have dominated the literary scene for the past ten years, the findings of this mixed method research study suggest that the fiction did more than entertain. It suggests that the fiction inspired and enlightened the reformist young adults of the present day. 